\title{
Ligand Substitution Dynamics
}

\author{
Substitution of a ligand in an inner sphere complex by an outside group \\ is the most fundamental reaction in metal ion chemistry
}

\section{Harry B. Gray}

\section{Cooper H. Langford}

O the 103 known elements, 83 are classified as metals. Much of the chemistry of this very large and diverse family of elements is the chemistry of metals as ions in solution. This includes some of those most familiar of all chemical reactions that we meet in our first introduction to chemistry: the precipitation of halides as their silver salts for identification; the changes of color of copper ion solution as ammonia is added; and many more. Metal ions in solution are always bound to other molecules or negative ions. Species capable of good binding to metal ions are referred to as ligands and may be solvent molecules or other good coordinating groups. The metal plus the most firmly bound ligands make up an aggregate species called an inner sphere complex. Species immediately outside the inner sphere complex are in the "outer sphere" environment.

Such complex compounds of metals play key roles in important chemical processes. Hemoglobin, the oxygen carrier of blood, is an iron complex. The green pigment of plants, chlorophyll, is a similar compound of magnesium. Vitamin $\mathrm{B}_{12}$ contains a cobalt ion bound to another elaborate ligand system. Many catalysts important to chemical synthesis are metal ion complexes, and metal complexes intervene in most electroplating processes.

If we are to understand and control the chemistry of metal ions in solution, we must understand the processes by which their complexes are formed and interconverted. This is most often a matter of the replacement of one coordinated ligand by another. The substitution of a ligand in the inner sphere (leaving group) by an outside group (entering group) is the most fundamental of the reactions in metal ion chemistry. In fact, all discussions of reactions of metal complexes hinge on an understanding of the dynamics of their ligand substitution process, since it is an ever present possibility.

To attempt a general theory of ligand substitution dynamics seems a formidable task, since so many elements of such diverse properties fall within the scope of the undertaking. However, substantial progress has been made, especially in recent years, because of a fascinating convergence of:

- Results of studies of certain model systems by traditional methods for analysis of rate and mechanism.

- Results over a broad time range made available by application of new fast reaction techniques developed largely by Prof. Manfred Eigen and his collaborators in West Germany.

- Results of applications of improved electronic structural models for metal complexes to give added power to theoretical correlations.

In this article we outline some recent advances in the understanding of ligand substitution dynamics to reveal the effectiveness of the interplay of new and old techniques with fresh theoretical insights.

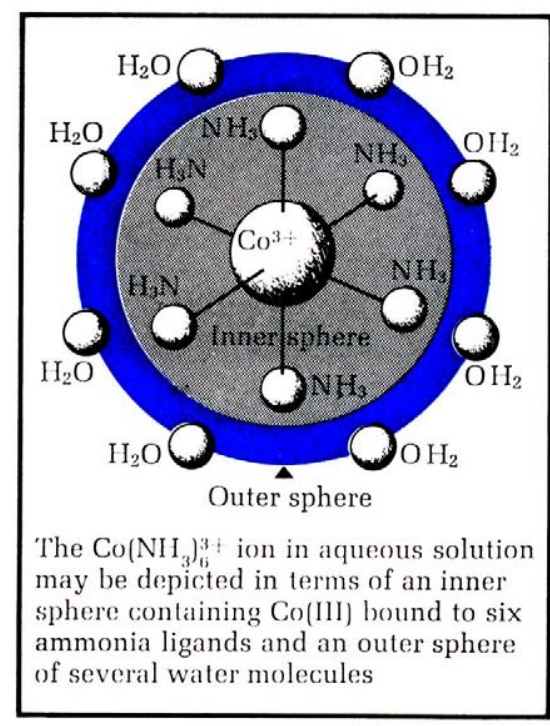

\section{Mechanistic language}

To approach an understanding of ligand substitution processes, it is first necessary to catalog the kinds of experiments which are available in the armamentarium of the "chemical dynamicist" interested in these problems and to consider what sorts of information these experiments provide. Commonly, a student of chemical dynamics studies reaction rates. But such studies may be approached from two points of view. First, it is possible to analyze the rate law for a reaction, which is the differential equation relating rate to reactant concentrations. This allows determination of the species which are present in the transition state of the reaction. Second, if it is assumed that a series of reactions proceeds by related mechanisms, the rates of the reactions may be compared and the energetic factors in activation inferred. In other words, it may be possible to consider the role of a variable entering group in a substitution and determine from the observed rates whether the entering group plays a role in determining the activation energy for substitution. Reaction mechanisms for substitution processes may be classified with respect to these types of experiments. A useful classification which considers reaction types that can be defined "operationally" is constructed readily when classification with respect to each of the two types of experiments is approached separately.

Careful study of the reaction rate law leads to identification of the reactant species which are components in the transition state or participate in reaction steps preceding the transition state. In reasonably favorable circumstances, this leads, in turn, to identification of the number of elementary steps necessary for the accomplishment of the overall reaction. Substitutions may follow one of three distinct, simple patterns: dissociative (D), associative (A), and interchange (I). The dissociative reaction is a two-step substitution involving the initial formation of an intermediate of reduced coordination number. The associative substitution proceeds in two steps through initial formation of an intermediate of increased coordination number. The interchange pattern is a substitution in a singlc step. 

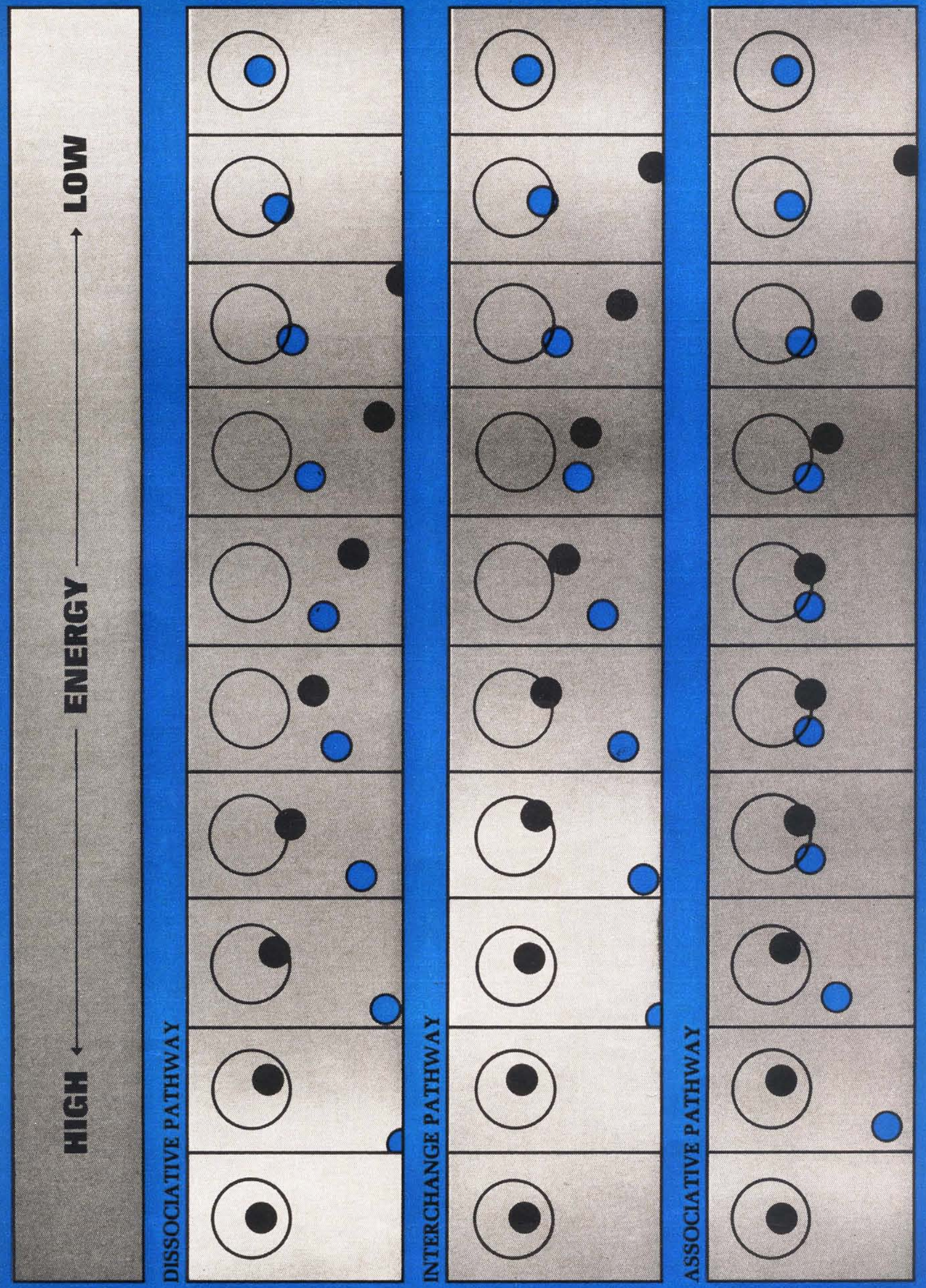


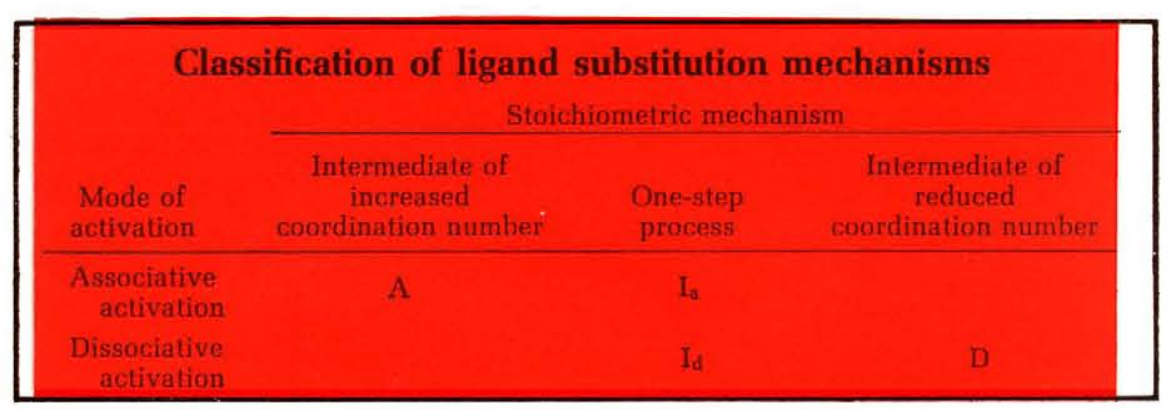

Ligand substitutions may follow one of three mechanisms
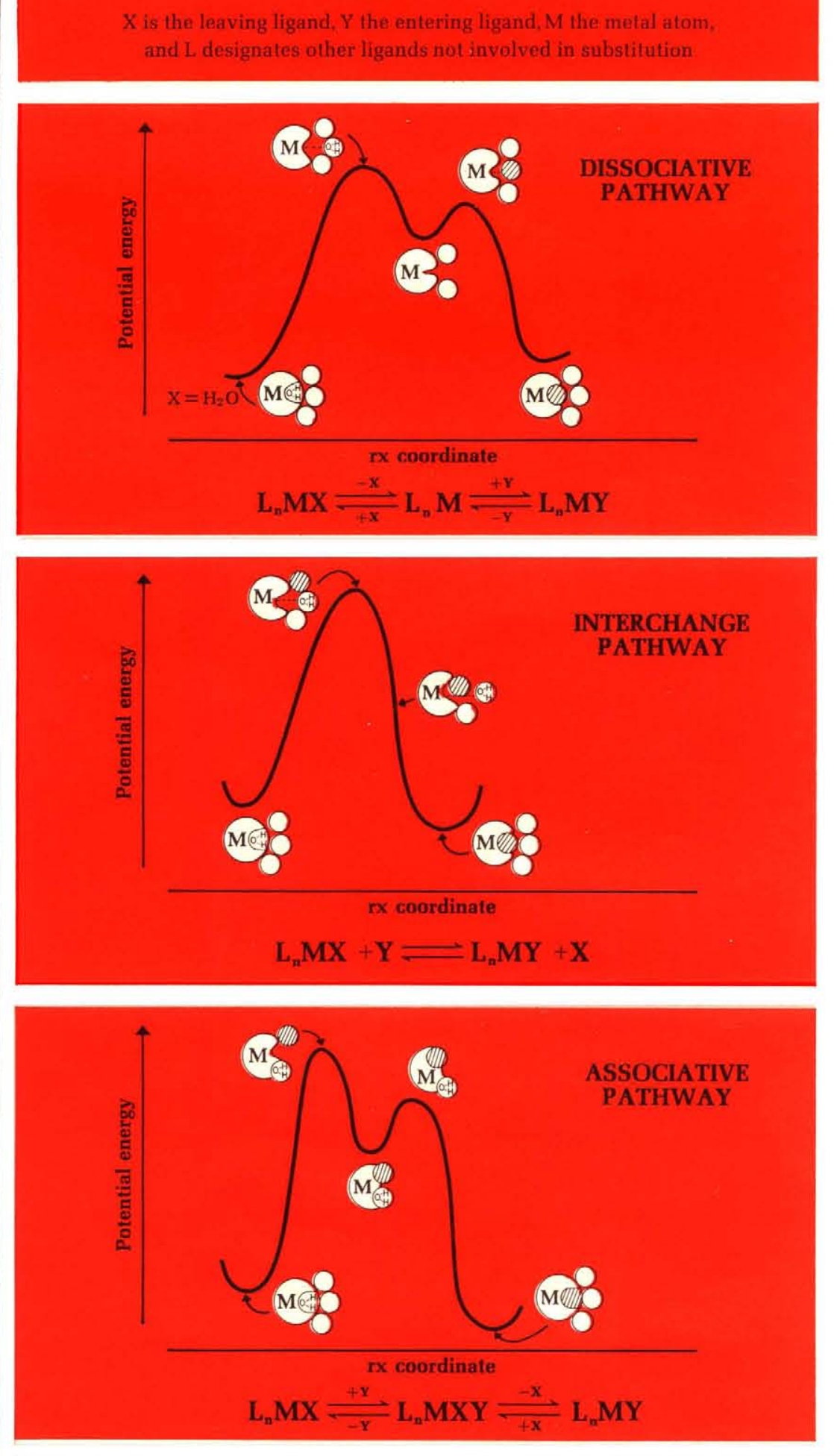

Turning to comparison of rates of related substitution reactions, the most important single issue is the effect of the entering group. If the rate of a substitution is dependent upon the miture of the entering group, clearly the process of breaking the bond to the leaving group is assisted by the newly forming bond. If the rate of substitution is quite insensitive to the nature of the entering group, it is difficult to imagine that binding of the entering group is assisting substitution. In the second case, the complex must accumulate sufficient energy by thermal fluctuations to "dissociate" the leaving group. Because these two types of activation processes occur in the $A$ and $D$ paths, respectively, they are designated the $a$ and $d$ modes of activation. Interchange processes may employ cither activation model $\mathrm{I}_{\mathrm{a}}$ or $\mathrm{I}_{\mathrm{l}}$.

An alternative approach to classifying substitutions which differs from the present scheme (see table) is the scheme borrowed from discussion of nucleophilic substitution reactions of organic chemistry. The D process may be designated $\mathrm{S}_{\mathrm{N}} 1$ (substitution, nucleophilic, unimolecular) and the $A$ process $S_{\mathrm{N}} 2$ (substitution, nucleophilic, bimolecular). This classification is widely used but may be argued to be infelicitous for some I reactions. AII I reactions are "bimolecular" in the sense that both the substrate complex and the entering group must be participants in the transition state. But the bimolecularity may be quite accidental. An $I_{d}$ process is analogous to a $D$ process in that the transition state is achieved by breaking the bord to the leaving group. If the residual moicty left behind when the bond is broken is noticeably stable, an intermediate is formed which may survive long enough to react selectively and a two-step $D$ reaction is observed. If, however, the residual moiety left after dissociation is highly energetic, it may not be able to survive long enough to react with any ligand except those in its immediate outer sphere "solvation" shell. An $\mathrm{I}_{t}$ reaction which is "accidentally" bimolecular is the result. The close analogy between the $\mathrm{D}$ and $I_{11}$ processes in terms of mode of activation is preserved in the $\mathrm{S}_{\mathrm{N}} \mathrm{I}-\mathrm{S}_{\mathrm{N}} 2$ classification scheme only by redefining the concept of molecularity to make it correspond to the number of species changing covalency in the reaction step. Then $D$ and $I_{13}$ reactions are $S_{X} l$. The price of this maneuver is to make molecularity a nonoperational concept. Molecularity then mav no longer be determined from raie laws. In this article we will employ the scheme shown in the table because mechanisms on the D-I $\mathrm{I}_{i 3}$ borderline have turned out to be extremely common in ligand substitutions. 

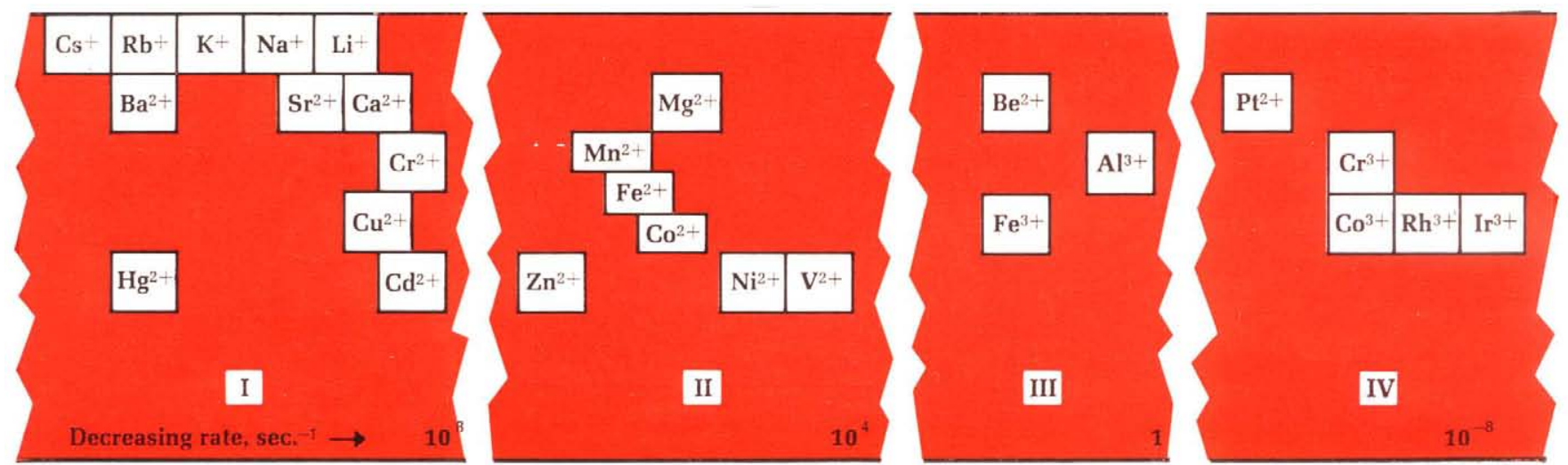

\section{Substitution time scale}

Metal ions in aqueous solution may be placed into four arbitrary classes based on the magnitudes of the rate constants for substitutional processes involving their complexes. For this discussion we are concerned with reactions where the leaving group $\mathrm{X}=$ II..O, the solvent is water, and the other inner sphere ligands $\left(\mathrm{L}_{12}\right)$ are also $\mathrm{H}_{2} \mathrm{O}$ molecules. Four categories on a time scale are defined as:

- Class I. Exchange of water is very fast; most, even "fast," kinetic techniques are not applicable. First order rate constants are about $10^{3}$ $\mathrm{sec}^{-1}$ or greater. Included in this group are the alkali metal ions and the alkaline earth metal ions except $\mathrm{Mg}^{2}+$ and $\mathrm{Be}^{2-} \div$.

- Class II. The first order rate constant for water exchange is $10^{4}$ to $10^{3}$ sec. ${ }^{1}$ Dipositive transition metal ions plis the tripositive rare earth ions are in this class, along with $\mathrm{Mg}^{2+}$. Most ions display characteristic rates independent of the entering group.

- Class III. First order rate constants here are 1 to $10^{4} \mathrm{sec}^{-1}$ Most of the tripositive transition metal ions such as $\mathrm{Fe}^{3+}$ are in this class as are $\mathrm{Be}^{2} \div$ - and $\mathrm{Al}: \div$.

- Class IV. Complexes of Class IV ions are relatively inert; first order rate constants are commonly between $10^{1}$ and $10^{-9} \mathrm{sec}^{1}$ Prominent members include $\mathrm{Co}^{3+}, \mathrm{Cr}^{3+}$, and $\mathrm{Pt}^{2+}$.

Before turning to finer mechanistic details, we will examine the reasons for the dramatic differences in substitutional reactivity of the metal ions. For example, a factor of some $10^{16}$ in rate separates $\mathrm{K}\left(\mathrm{H}_{2} \mathrm{O}\right)_{x}{ }^{+}$and $\mathrm{Cr}$ $\left(\mathrm{H}_{2} \mathrm{O}\right)_{6}{ }^{3+}$. Most of the large differences can be explained on the basis of a simple electrostatic model of binding, because there is a rough correlation between the charge-to-size ratio of the ion and its position in the reactivity table. Other factors being equal, we should expect that small, highly charged cations should firmly bind a relatively nonpolarizable ligand such as water. Moreover, the higher the charge, the stronger the binding should be. Thus, Class I consists of all the monopositive and several large dipositive ions. Class II is composed mainly of the smaller dipositive ions and several large tripositive ones. Class III includes the very small $\mathrm{Be}^{2+}$ and two small tripositive ions, $\mathrm{Fe}^{3+}$ and $\mathrm{Al}^{3+}$. The very low reactivity of the Class IV ions cannot be understood in terms of this simple model. However, we recognize the ions in this class as those having specially stable $\mathrm{d}^{\mathbf{n}}$ ground-state electronic structures in octahedral and square planar coordination environments. In octahedral structures, the $\mathrm{d}^{\mathrm{n}}$ configurations $\mathrm{d}^{3}$ and $\mathrm{d}^{\text {f }}$ (low spin) have special stability, $\mathrm{d}^{8}$ (low spin) is a notably stable ground state for square planar coordination. Class IV ions, then, all have extra ligand-field ground-state stabilization and a resulting low substitutional reactivity.

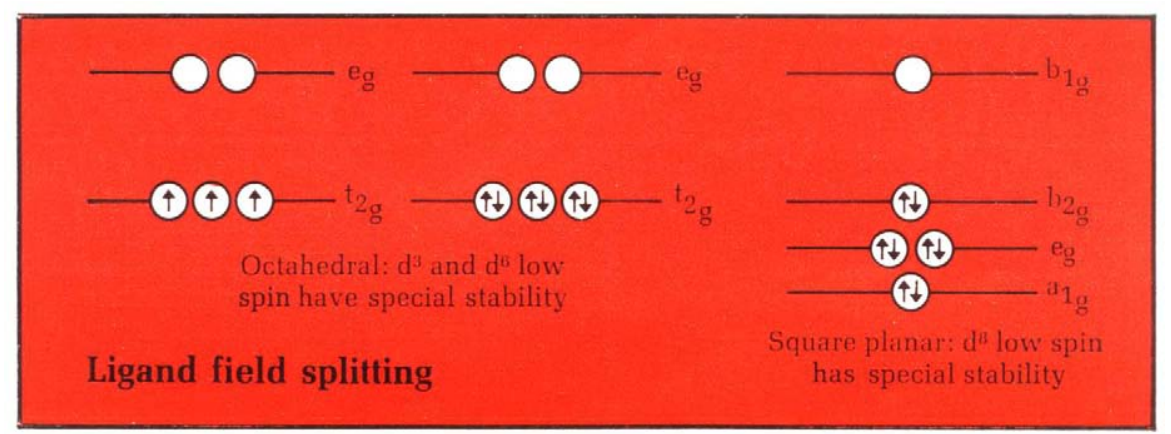

\section{Mode! systems}

Class IV complexes have been studied extensively because the ratcs are slow enough to permit using conrentional kinetic techniques. Rate constants for exchange of water at $25^{2} \mathrm{C}$. in three exemplary cases are:

- Octahedral do low spin; Co$\left(\mathrm{NH}_{3}\right)_{1} \mathrm{OH}_{2}{ }^{3+} ; \mathrm{k}=6 \times 10^{-6}$ sec. $^{-1}$

- Octahedral d $\mathrm{d}^{3} \mathrm{Cr}\left(\mathrm{OH}_{2}\right)_{8}{ }^{3+} ; 6 \mathrm{k}$ $=2 \times 10^{-5}$ sec. $^{-1}$

- Square planar d8 low spin; Pt(dien) $\mathrm{OH}_{2}^{2+}: \mathrm{k}=1 \times 10^{-3} \mathrm{sec}^{-1}$

The ligand "dien" is diethylenetriamine: $\mathrm{NH}_{2}-\left(\mathrm{CH}_{2}\right)_{2}-\mathrm{N}-\left(\mathrm{CH}_{2}\right)_{2}-$ $\mathrm{NH}_{2}$.

We shall now explore the types of experiments which have led to detailed understanding of cobalt(III) and platinum(II) reactions like the ones above, because it is emerging that the octahedral complexes of cobalt (III) and the square planar complexes of platinum(II) have functioned admirably as models for the development of key concepts and experiments for understanding ligind substitution processes in general.

\section{Actication modes}

The mode of activation may be deduced from studies of the rate dependence on the nature of the entering group. In colbalt(III) substitutions, it is a very general result that, exclud. ing hydroxide ion, variation of the entering group does not significantly change the rate of reaction. Rate laws commonly are strictly first order, reflecting the fact that, in the absence of entering group effects, the must populous entering group-the solventusually enters. Other ligands appear in the rate law only if a solvent molecule is the leaving group. This behavior clearly indicates failure to discriminate among entering groups and is characteristic of the dissociative mode of activation. 
In contrast, rates of platinum(II) substitutions are strongly dependent on the entering group. A reaction which has received much attention recently is:

$$
\begin{aligned}
& \text { trans- } \mathrm{Pt}(\mathrm{pip}){ }_{2} \mathrm{Cl}_{2}+\mathrm{Y}-\rightarrow \\
& \text { trans- } \mathrm{Pt}(\mathrm{pip}){ }_{2}(\mathrm{Cl})(\mathrm{Y})+\mathrm{Cl}^{-} \\
& \text {where pip }=\text { piperidine }
\end{aligned}
$$

The rate law for this reaction has the form:

$$
\text { Rate }=\left(\mathrm{k}_{1}+\mathrm{k}_{2}[\mathrm{Y}]\right) \text { [substrate] }
$$

The second order term $\left(k_{2}\right)$ is what we would expect for an associative mode of activation. All evidence suggests that the first order term $\left(k_{1}\right)$ does not indicate a concurrent dissociative mechanism, rather another associative process involving the solvent. The following are values of $k_{2}$ for various entering groups for the substrate trans-dichloropiperidineplatinum(II) in ethanol at $30^{\circ} \mathrm{C}$., taken from very recent work by Prof. Umberto Belluco and his coworkers of Padcva, Italy:

$\begin{array}{lc}\mathrm{Y} & \mathrm{k}_{2} \times 10^{3}, \mathrm{M}^{-1} \text { sec. }{ }^{-1} \\ { }^{36 \mathrm{Cl}^{-}} & 0.9 \\ \mathrm{Br}^{-} & 6.9 \\ \mathrm{SCN}^{-} & 400 \\ \mathrm{SeCN}- & 3300 \\ \mathrm{SC}\left(\mathrm{NH}_{2}\right)_{2} & 4600\end{array}$

These rate data may be considered definitive for an associative mode of activation. The magnitude of the rate constant $k_{2}$ is influenced profoundly by the nature of $\mathrm{Y}$. Experiments of this type have led to an ordering of entering groups for platinum(II) substitutions on a generalized relative rate scale:

$$
\begin{aligned}
& \frac{\mathrm{PR}_{3}>\mathrm{CN}^{-}, \mathrm{SC}\left(\mathrm{NH}_{2}\right)_{2}, \mathrm{SeCN}^{-}>}{10^{6}} \mathrm{SO}_{3}^{2-}, \mathrm{SCN}^{-}, \mathrm{I}^{-}> \\
& 10^{4} \\
& \begin{array}{cc}
\mathrm{Br}^{-}, \mathrm{N}_{3}^{-}, \mathrm{NO}_{2}^{-}, \mathrm{py}, \mathrm{NH}_{3}, \mathrm{Cl}^{-}> & \mathrm{OR}^{-} \\
1 & 0.1 ?
\end{array}
\end{aligned}
$$

In both $a$ and $d$ modes of activation the bond to the leaving group must be "perturbed" in the transition state. In the dissociative mode, the effect should be most dramatic (and independent of the entering group). But for associative activation, the leaving group effect should be variable, being of great importance for poor entering groups.

For cobalt(III) substrates, there are enough equilibrium and rate data available to show a linear free energy correlation $(\log \mathrm{k} v \mathrm{~s} . \log \mathrm{K})$ for the substitution reaction:

$$
\begin{aligned}
& \mathrm{Co}\left(\mathrm{NH}_{3}\right)_{5} \mathrm{X}^{2+}+\mathrm{H}_{2} \mathrm{O} \rightleftharpoons \\
& \quad \mathrm{Co}\left(\mathrm{NH}_{3}\right)_{5} \mathrm{OH}_{2}{ }^{3+}+\mathrm{X}^{-}
\end{aligned}
$$

In the expression $\Delta \Delta G^{\ddagger}=\beta \Delta\left(\Delta G^{\circ}\right)$, $\beta=1.0$, supporting dissociative activation.

(1)

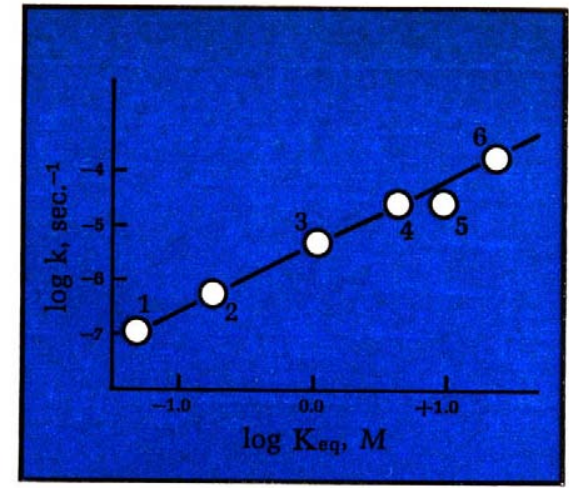

This plot of log rate constant vs. Iog of equilibrium constant is for the acid hydrolysis reaction of $\left[\mathrm{Co}\left(\mathrm{NH}_{3}\right)_{5} \mathrm{X}\right]^{2+}$ ions. Measurements were made at $25.0^{\circ}$ C. Points are: $1, \mathrm{X}^{-}=\mathrm{F}^{-} ; 2$, $\mathrm{X}^{-}=\mathrm{H}_{2} \mathrm{PO}_{4}^{-} ; 3, \mathrm{X}^{-}=\mathrm{Cl}^{-} ; 4, \mathrm{X}^{-}=$ $\mathrm{Br} ; 5, X^{-}=\mathrm{I}^{-}$; and $6, \mathrm{X}^{-}=\mathrm{NO}_{3}^{-}$. The log of a rate or equilibrium constant is proportional to a free energy change. Note that each change of $1.0 \mathrm{kcal}$. in the overall free energy change for the reaction is paralleled by a $1.0-\mathrm{kcal}$. change in the free energy required for activation. It is only the leaving anion that is being varied. As the leaving anion is varied, the only significant change in the overall reaction is the change in the solvated anion produced as a product. The linear free energy relationship implies that the transition state resembles closely the product with respect to this variation. It follows that the leaving group must be functioning very nearly as a solvated anion in the transition state; that is, effective dissociation has occurred 
Other relative rate studies are consistent with different modes of activation for the model cobalt(III) and platinum(II) substrates. Two of particular interest which may be acceptable for general use are steric effects and substrate-charge effects. Generally, steric crowding due to substituents on the nonlabile ligands rapidly accelerates cobalt(III) substitutions, where the transition state is less crotcded. In platinum(II) cases, however, crowding in the ground state slows the reaction enormously, consistent with associative activation in the unhindered cases. Indeed, the most sterically hindered platinum(II) and palladium(II) complexes may be forced into dissociative activation. This is presumably the case for the complex $\mathrm{Pd}\left(\mathrm{Et}_{4}\right.$ dien $) \mathrm{Cl}+\left[\mathrm{Et}_{4}\right.$ dien is $\left(\mathrm{C}_{2} \mathrm{H}_{3}\right)_{2} \mathrm{~N}-\left(\mathrm{CH}_{2}\right)_{2}-\mathrm{N}(\mathrm{H})-\left(\mathrm{CH}_{2}\right)_{2}$ $\left.\mathrm{N}\left(\mathrm{C}_{2} \mathrm{H}_{i}\right)_{2}\right]$, which reacts $10^{4}$ times slower than unhindered $\mathrm{Pd}($ dien $) \mathrm{Cl}+$ in water, and at least $10^{5}$ times slower in dimethylsulfoxide. Interestingly, the rates for $\mathrm{Pd}\left(\mathrm{Et}_{4}\right.$ dien $) \mathrm{CI}^{+}$are about the same as those for analogous rhodium(III) substitutions.

The substrate-charge effect for cobalt (III) and platinum(II) systems is:

The much larger effect of substrate charge is consistent with dissociative activation in the cobalt(III) case.

The models cobalt(III) and platinum(II) allow us to extract some useful generalizations concerning relative rates expected for the two different modes of activation. These generalixations are:

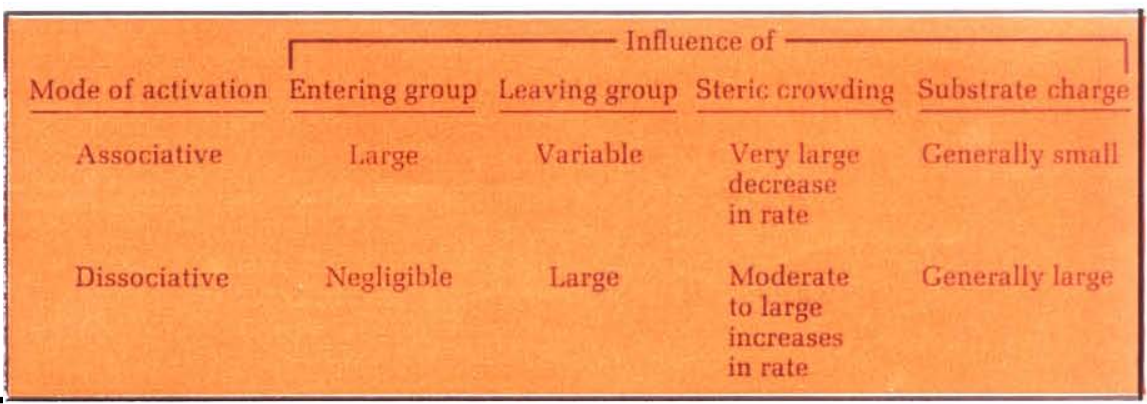

\section{Trans effect in $\mathrm{Pt}(\boldsymbol{I})$ substitutions}

A particularly significant influence on rates due to nonlabile ligands is the trans effect in platinum(II) substitutions. The presence of this effect allows us to say more about the structure of the transition state. From experiments, we know that in platinum(II) substitutions the rate of reaction depends strongly on the nature of the ligand in trans position to the leaving group. Conversely, there is little or no influence from the two cis ligands. From this result we can extend the mechanism of associative activation to include a definite structural arrangement of ligands in the transition state. A particularly attractive model assumes trigonal bipyramidal

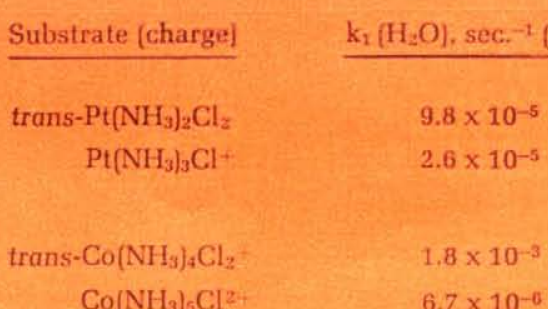
Ratio, $\frac{\left.\frac{\mathrm{n}^{+}}{(\mathrm{n}+1}\right)^{+}}{}$

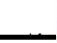


The advantage of this model is that it allows an understanding of large effects due to entering, leaving, and trans groups and relatively small effects due to the cis groups. Specifically, there are large orbital changes in going from the ground state for the three ligands present in the trigonal plane.

The observed trans-effect order of ligands, on a relative rate scale, is set out below. Two factors are of possibly major importance in giving this effect.

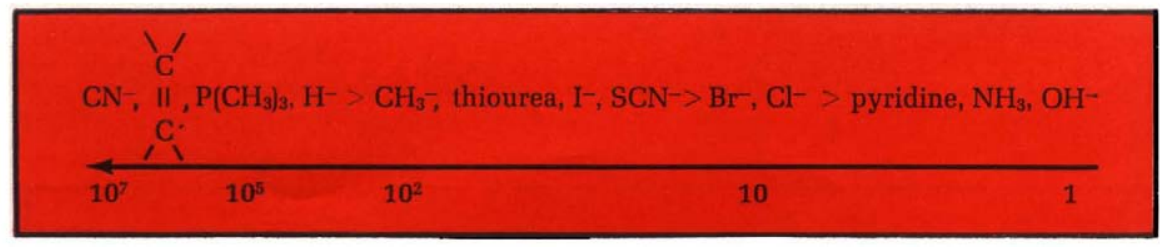

Trans-labilizing order of ligands

According to the $\pi$-bonding theory, the trans-labilizing order parallels the order of $\pi$-electron accepting ability of the labilizing ligand. This was reasoned on the basis of the idea that upon forming the trigonal bipyramidal intermediate from the square planar structure four rather than three $d$ orbitals would then have the proper symmetry for $\pi$ interaction with the ligands. A trans group with empty, reasonably stable $\pi$-symmetry orbitals would then lower the energy of the transition state simply by accommodating the excess electronic charge around the central metal atom due to the entering ligand. The finding that groups such as $\mathrm{PR}_{3}, \mathrm{H}^{-}$, and $\mathrm{CH}_{3}-$ are good trans-labilizing ligands suggests that other factors are also at play. Here again we infer a role for platinum (II) $6 \mathrm{p}$ orbitals. If the trans group has strong $\sigma$ interaction with the metal $p$ orbital (which $\mathrm{H}^{-}$and $\mathrm{CH}_{3}$ - should have from overlap considerations), then the bond to the leaving group will be relatively weak in the square planar structure. In the transition state the leaving and entering groups share the previously unoccupied $6 \mathrm{p}_{\mathrm{z}}$ orbital; the driving force of the reaction is provided by the tendency of the trans ligand ( $\mathrm{T}$ ) to own as much of its own p orbital as possible. This is shown by:

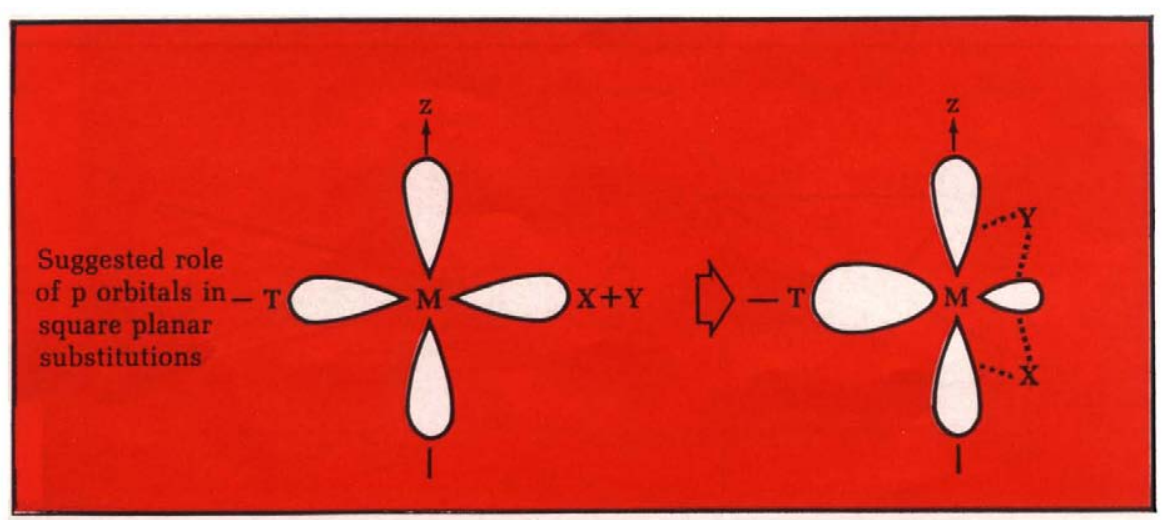

Thus far we have not looked beyond the transition state in either cobalt(III) or platinum(II) substitutions. The most difficult area of mechanistic study involves characterization of the number of elementary steps leading to products. In the cobalt(III) case, three studies may be singled out as exemplary in the establishment of stoichiometric mechanism.

In the case of $\mathrm{Co}\left(\mathrm{NH}_{3}\right)_{5} \mathrm{OH}_{2}{ }^{3+}$ as substrate, rates of water replacement by ligands $\mathrm{Y}$ reach limiting values when the $\left[\mathrm{Co}\left(\mathrm{NH}_{3}\right)_{5} \mathrm{OH}_{2}{ }^{3+}, \mathrm{Y}-\right]$ ion pair forms. These limiting rates do not depend significantly on the nature of $\mathrm{Y}$, and, furthermore, they are lower than the rate of ${ }^{18} \mathrm{OH}_{2}$ exchange. A satisfactory picture emerges by assuming that one of perhaps eight positions in the outer sphere is occupied by $\mathrm{Y}$ and, therefore, $\mathrm{k}(\mathrm{Y}) \cong 1 / 8 \mathrm{k}\left(\mathrm{H}_{2} \mathrm{O}\right)$ for an $I_{d}$ mechanism. If the reactions were $\mathrm{D}$, the limiting rates would have to reach the water exchange rate.

Two studies have emerged as models for $\mathrm{D}$ mechanisms. The substitutions of $\mathrm{Co}(\mathrm{CN})_{5} \mathrm{OH}_{2}{ }^{2-}$ and $\mathrm{Co}\left(\mathrm{SO}_{3}\right)\left(\mathrm{NH}_{3}\right)_{5}+$ by various entering groups may be fit to rate laws appropriate to two-step $\mathrm{D}$ reactions. Selective reactivity of the five-coordinate intermediate is observed. Furthermore, the rate of $\mathrm{H}_{2} \mathrm{O}$ exchange in $\mathrm{Co}(\mathrm{CN})_{5} \mathrm{OH}_{2}{ }^{2-}$ is known with fair precision and is consistent with the two-step D process.

In the platinum(II) substitutions, there is strong evidence external to rate studies in support of the stable five-coordinate intermediates required along two-step A pathways. The evidence is the existence of several stable trigonal bipyramidal platinum(II), palladium(II), and nickel(II) complexes. Two complexes of relevance are $\mathrm{Ni}(\mathrm{CN})_{5}^{3-}$ and $\mathrm{Pt}\left(\mathrm{SnCl}_{3}\right)_{5}^{3-}$.

Finally, then, we may come to strong conclusions with respect to the modes of activation in cobalt (III) and platinum(II) systems. There is more uncertainty with respect to stoichiometric mechanism: A mechanisms are a solid choice for platinum(II) systems, but cobalt(III) systems are so near the $\mathrm{D}-\mathrm{I}_{\mathrm{d}}$ borderline that crossover has been observed and future cases will need to be judged on an individual basis. Considering ions more generally, it appears that modes of activation may be assigned with some confidence now. Square planar complexes in general appear to employ the $a$ mode. The reactions of the Class II ions (water exchange characteristic time $10^{-4}$ to $10^{-8}$ sec.), which are entering group insensitive, strongly suggest the $d$ mode. Work on the analysis of stoichiometric mechanism in fast reactions is just beginning. 


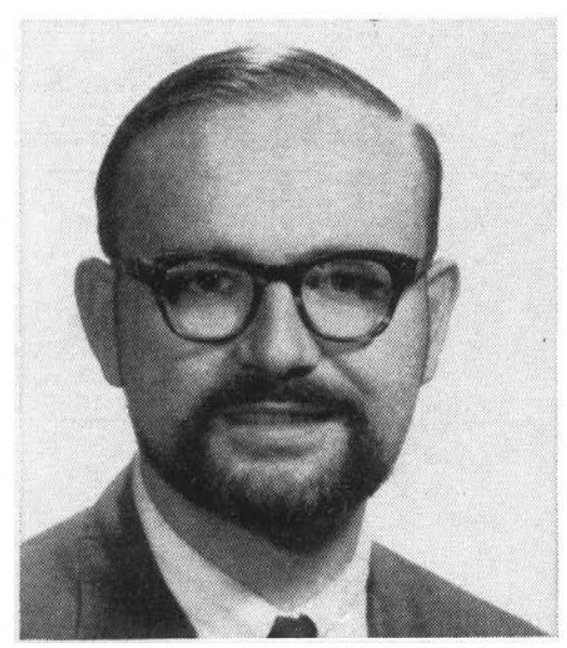

COOPER H. LANGFORD received an A.B. from Harvard University in 1956 and $a$ Ph.D. in physical chemistry from Northwestern University in 1960. During 1959-60 he worked as a $\mathrm{Na}$ tional Science Foundation postdoctoral fellow at University College London with Dr. Martin Tobe and became interested in inorganic reaction mechanisms. In the period 1960 to 1967 he was assistant and associate professor of chemistry at Amherst College and in the spring semester of 1964, visiting assistant professor of chemistry at Columbia University. In the fall of 1967 he became associate professor in the department of chemistry of Carleton University, Ottawa, Canada. His research interests have centered on ligand substitution reactions and solvation phenomena studied by classical and nuclear magnetic resonance techniques. He is an author of some 20 research papers in this field and coauthor with Prof. Gray of the book "Ligand Substitution Processes." $\mathrm{He}$ has been awarded an Alfred P. Sloan Foundation fellowship for 1968-70.

\section{Suggestions for further reading}

1. Basolo, F., and Pearson, R. G., "Mechanisms of Inorganic Reactions," 2nd ed., John Wiley \& Sons, Inc., New York, 1967.

2. Edwards, J. O., "Inorganic Reaction Mechanisms," W. A. Benjamin, Inc., New York, 1964.

3. Hunt, J. P., "Metal Ions in Aqueous Solution," W. A. Benjamin, Inc., New York, 1963.

4. Langford, C. H., and Gray, H. B., "Ligand Substitution Processes," W. A. Benjamin, Inc., New York, 1965 .

5. Orgel, L. E., "An Introduction to Transition-Metal Chemistry," 2nd ed., Methuen \& Co., Ltd., London, 1966.

6. Sykes, A. G., "Kinetics of Inorganic Reactions," Pergamon Press, Ltd., Oxford, 1966.

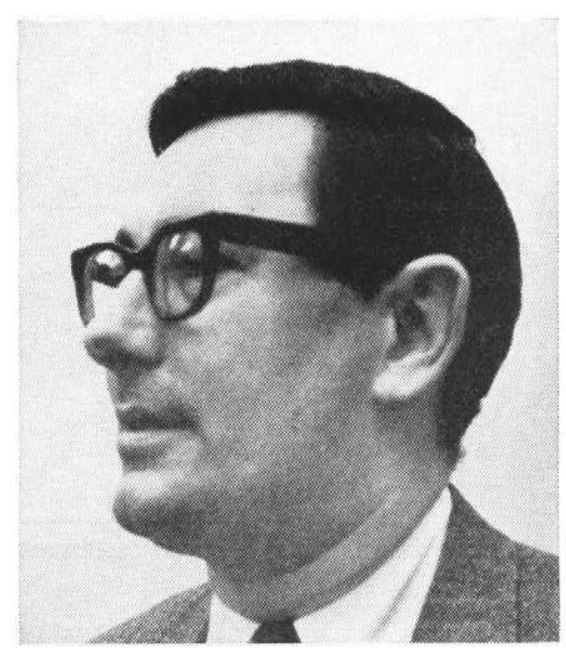

HARRY B. GRAY was born in Woodburn, Ky., in 1935. He received a B.S. from Western Kentucky University in 1957. He held Dow and $\mathrm{Na}$. tional Science Foundation fellowships at Northwestern University, where he received a Ph.D. in 1960. His research was carried out in physical inorganic chemistry under the direction of Prof. Ralph G. Pearson and Prof. Fred Basolo.

Dr. Gray was a National Science Foundation postdoctoral fellot in the University of Copenhagen during 1960-61. In Copenhagen, he was associated with Prof. Carl J. Ballhausen. In 1961, he joined the chemistry staff at Columbia University as assistant professor, in 1963 was promoted to associate professor, and 1965 to professor. In 1966, he joined the staff of the California Institute of Technology as professor of chemistry.

Dr. Gray has published approximately 90 papers and four books. His fith book, "Chemical Dynamics," coauthored with J. Dence and G. S. Hammond, will be published this year. $\mathrm{He}$ is a member of numerous honorary and professional organizations. His recent honors include an Alfred $P$. Sloan research fellowship, the E. C. Franklin Memorial Award, the Reilly Lectureship at the University of Notre Dame, the Venable Lectureship at the University of North Carolina, the Franklin Lectureship at the University of Kansas, and the Sloan Lectureship at the University of Alaska. At present, Dr. Gray is serving as chairman of the freshman committee on the Advisory Council of College Chemistry and as associate editor of Inorganica Chimica Acta.

His current research interests include inorganic reaction mechanisms, the preparation and characterization of new inorganic substances, and the interpretation of spectral and magnetic properties of transition melal complexes in terms of modern quantum mechanical theories of electronic structure.

\section{You can purchase reprints of C\&EN features}

Copies of this feature Ligand Sub. stitution Dynamics and selected other features are available.

\section{Ligand Substitution Dynamics}

Infrared Spectroscopy

Border Taxes

Organic Free Radicats

Some Chemical Glimpses of Evolution

Life Transcending Physics

and Chemistry

The Synthesis of Living Systems

The Chemistry of the

Actinides

Ion-Selective Electrodes

Molecular Photochemistry

The Chemistry of Flavor

1 to 49 copies -50 cents each 50 to 299 copies -40 cents each

Prices for larger quantities on re. quest

TO: REPRINT DEPARTMENT

ACS Publications

1155-l6th St. N.W.

Washington, D.C. 20036

FROM:

\section{$\overline{\text { Name }}$} copies _

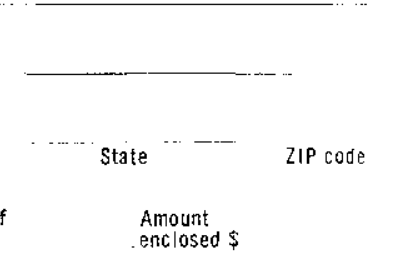




\section{DIRECTORY SECTION}

This scetion includes: CHEMICALS EXCHANGE-Chemicals, Resins, Gums, Oils, Waxes, Pigments, etc.: EQLIPMENT MART - Vew and Used Equipment, Instruments: Facilities for Plant and Laboratory; TECHNICAL SERVICFS-Consultants; Engineering,

Testing, Professional Services.
Advertising Rates: Space rate is $\$ 74$ per inch. Lower rates available on contract basis. An "inch" advertisement measures $7 / \mathrm{s}^{\prime \prime}$ deep on one column. Additional space in even lineal inch units. Maximum space-4" per Directory per issue. Set ads due 21 days in advance of publication; plated ads, 17 days.

\section{CHEMICALS EXCHANGE}

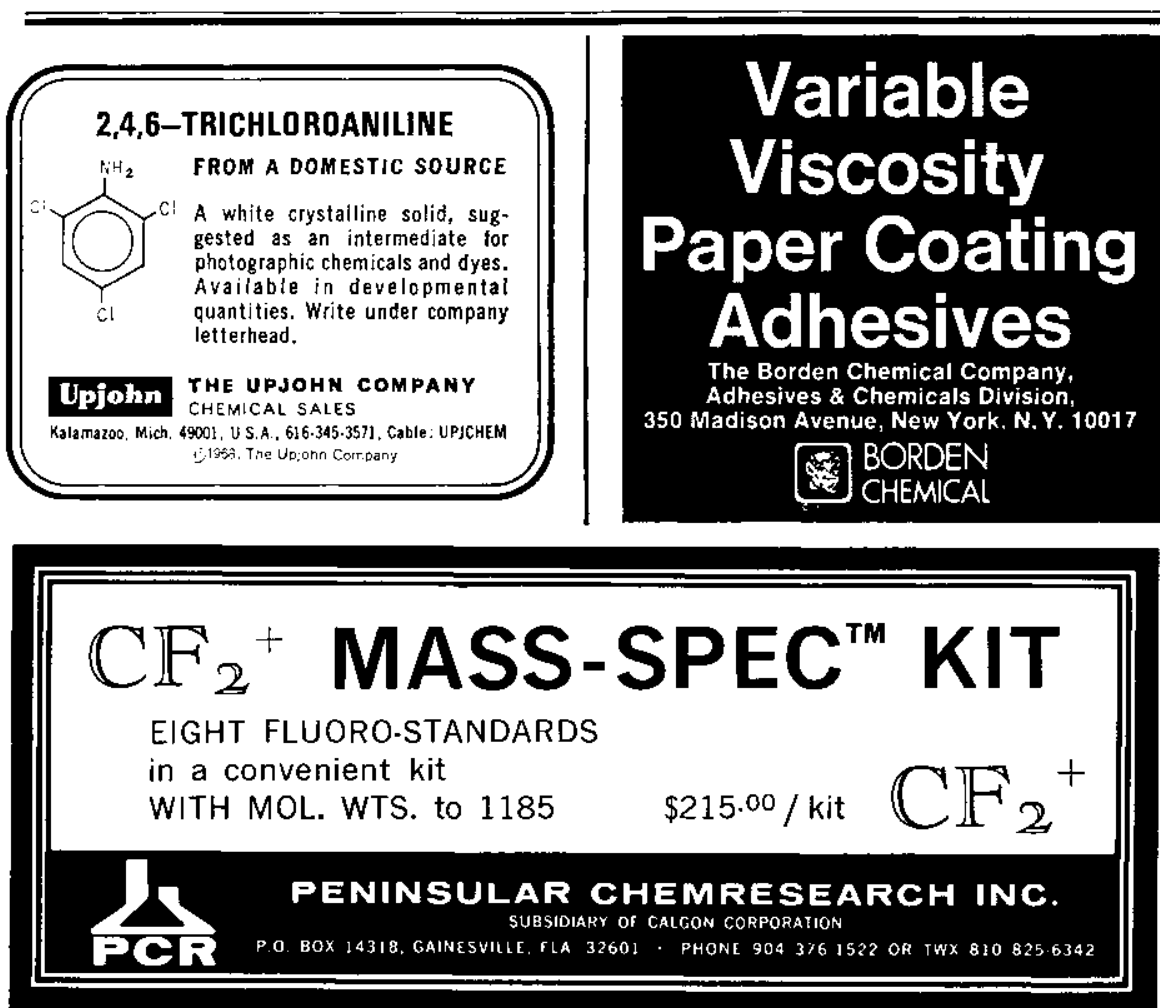

EQUIPMENT MART

FIRST IN WATER ANALYSIS 서묘

Write for Equipment Catalog HACH CHEMICAL COMPANY Ames, lowa 50010

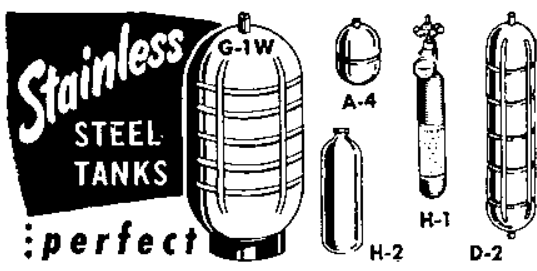

priced at far less than reproduction cost! Ideal for chemicals, gases, pneumatic use, bydraulics and liquids. HIGH PRESSURE TANKS, 500 PSI (1/4" pipe threads each end G-1W-12" $\times 24^{\prime \prime}$-has standup base G-1 for easy filling. $\$ 19.50$ D-2 6" x 24" Magnetic Type Stainless \$8.95 Many sizes in stock up to 3000 psi-write

Send Purchase Order. Terms $2 \% 10$ days, 30 days net. A. C. TANK CO., Dept. Z-468, P. O. Box A BURLINGTON, WIS. Phone 414-763-3311
TECHNICAL SERVICES

\begin{tabular}{|}
\hline MASS SPECTROSCOPY \\
IR-NMR-EPR \\
Compound Identification-Molecular W Wight \\
and Structure-Gas Analysis- Isistopic Analy- \\
sis-Techical Assistince Available. \\
WEST COAST TECHNICAL SERVICE \\
1049 S. San Gabriel BIvd., San Gabriel, Calif. 91776 \\
(213) 287-2657
\end{tabular}

SCHWARZKOPF
MICROANAIYTICAL LABORATORY
$56-19$ 37th Ave. Woodside, N.Y. 11377
Telephone: Code 212 , HAvemeyer $96248,9-6223$
Complete Analysis of Organic Compounds
Results within one week
Elements, Functional Groups, Molecular Weights
Plysical Constants, Spectra
ANALYSIS OF ORGANO METALLICS
BORO-FLUORO AND SILICON COMPOUNDS
Trace Analysis Microanalytical Research

\section{MOLECULAR WEIGHT STANDARDS} POLYMER ANALYSIS by

GEL PERMEATION CHROMATOG RAPHY OSMOMETRY, VISCOSITY and LIGHT DIFFERENTIAL THERMAL ANALYSIS ArRo Laboratories, Inc.

1107 West Jefferson Joliet, lllinois 60435 Jest Jefferson
Telephone $815-727-5436$
TECHNICAL SERVICES

\section{TRACE analysis by}

ATOMIC ABSORPTION SPECTROMETRY

-30 elements available-detection limits generally less than 1 ppon-interferences low-solu THORPE LABORATORIES-SINCE 1948

P.O. Box 842-Paso Robles-Calif. 93446 -dial direct: area 805, 238-2233

\begin{tabular}{c}
\hline ROBINETTE RESEARCH \\
LABORATORIES, INC. \\
Industrial Research Consultation \\
Technical Surveys \\
Product Development \\
Textile, Ion Exchange Technology \\
Chemical Market Resedrch \\
Berwyn, Po. Nlagasa 4-0601 Atea Code 215 \\
Member, Amer. Council Ind. Labs., Inc.
\end{tabular}

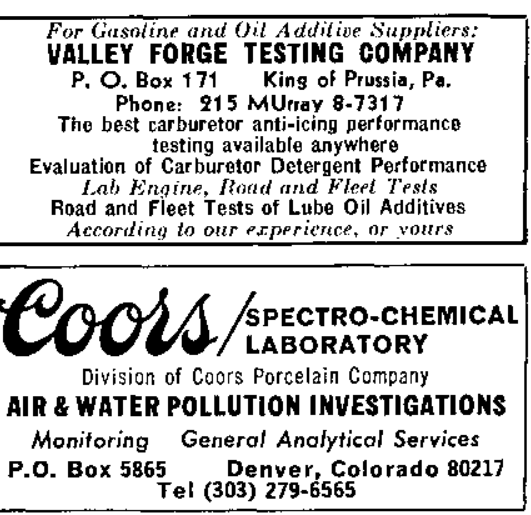

\section{ASSOCIATIONS \\ Continued from page 62}

Society of Plastics Engineers is cooperating with the university. Program includes technical papers and a molders' workshop. Write Engineering Dept., University Extension, University of Wisconsin, 432 North Lake St., Madison, Wis.

8th International Congress on HighSpeed Photography, Stockholm, Sweden, June 23 to 29 . Write Box 23, Stockholm 80, Sweden, by April 15.

\section{MEN AND MOLECULES}

released for broadcast after April 5 is titled the second barrier and features Dr. Lee Hood of NIH.

See "Men and Molecules" list. ings beginning on page 42 of C\&EN for Jan. 1 for stations broadcasting in your area. Each week $C \& E N$ announces here the "Men and Molecules" program to be released the following Friday. Call your local station to find out when specific programs you are interested in will be broadcast. 